\title{
Development of Continuous Galvanization-compatible Martensitic Steel
}

\author{
Y. F. Gong ${ }^{1}$, T. J. Song ${ }^{1}$, Han S. Kim ${ }^{1}$, J. H. Kwak', and B. C. De Cooman, ${ }^{1,+}$ \\ ${ }^{1}$ Materials Design Laboratory, Graduate Institute of Ferrous Technology, \\ Pohang University of Science and Technology, Pohang, South Korea \\ ${ }^{2}$ Automotive Steel Research Group, POSCO Gwangyang Works, Gwangyang, South Korea
}

(Received August 3, 2009; No Revision; Accepted February 24, 2012)

\begin{abstract}
The development of martensitic grades which can be processed in continuous galvanizing lines requires the reduction of the oxides formed on the steel during the hot dip process. This reduction mechanism was investigated in detail by means of High Resolution Transmission Electron Microscopy (HR-TEM) of cross-sectional samples. Annealing of a martensitic steel in a $10 \% \mathrm{H}_{2}+\mathrm{N}_{2}$ atmosphere with the dew point of $-35{ }^{\circ} \mathrm{C}$ resulted in the formation of a thin $c$-xMnO. $\mathrm{SiO}_{2}(\mathrm{x}>1)$ oxide film and amorphous $a-\mathrm{xMnO} \cdot \mathrm{SiO}_{2}$ oxide particles on the surface. During the hot dip galvanizing in $\mathrm{Zn}-0.13 \% \mathrm{Al}$, the thin $c-\mathrm{xMnO} \cdot \mathrm{SiO}_{2}(\mathrm{x}>1)$ oxide film was reduced by the $\mathrm{Al}$. The $a$-xMnO. $\mathrm{SiO}_{2}(\mathrm{x}<0.9)$ and $a-\mathrm{SiO}_{2}$ oxides however remained embedded in the $\mathrm{Zn}$ coating close to the steel/coating interface. No $\mathrm{Fe}_{2} \mathrm{Al}_{5-\mathrm{x}} \mathrm{Zn}_{\mathrm{x}}$ inhibition layer formation was observed. During hot dip galvanizing in $\mathrm{Zn}-0.20 \% \mathrm{Al}$, the $c-\mathrm{xMnO} \cdot \mathrm{SiO}_{2}(\mathrm{x}>1)$ oxide film was also reduced and the amorphous $a$-xMnO. $\mathrm{SiO}_{2}$ and $a-\mathrm{SiO}_{2}$ particles were embedded in the $\mathrm{Fe}_{2} \mathrm{Al}_{5-\mathrm{x}} \mathrm{Zn}_{\mathrm{x}}$ inhibition layer formed at the steel/coating interface during hot dipping. The results clearly show that $\mathrm{Al}$ in the liquid $\mathrm{Zn}$ bath can reduce the crystalline $c$-xMn. $\mathrm{SiO}_{2}(\mathrm{x}>1)$ oxides but not the amorphous $a$-xMnO.SiO ${ }_{2}(\mathrm{x}<0.9)$ and $a$ - $\mathrm{SiO}_{2}$ oxides. These oxides remain embedded in the $\mathrm{Zn}$ layer or in the inhibition layer, making it possible to apply a $\mathrm{Zn}$ or $\mathrm{Zn}$-alloy coating on martensitic steel by hot dipping. The hot dipping process was also found to deteriorate the mechanical properties, independently of the $\mathrm{Zn}$ bath composition.
\end{abstract}

Keywords : martensitic steel, hot dip galvanizing, oxides, HR-TEM

\section{Introduction}

Current automotive body-in-white designs place a great emphasis on passenger safety aspects. Whereas DP and TRIP steels are ideally suited for energy absorption in frontal collision, martensitic grades must be used for anti-intrusion barriers to protect passengers in case of side collision or roll over. Furthermore, the corrosion resistance must be ensured for any material used in a structural part of automotive components. In this regard, continuous hotdip galvanization-compatible martensitic steel is a very promising material, which can provide ultra-high strength and a cost-effective approach to perforation corrosion resistance. Conventional hot-dip coating processes, however, can result in micro-structural changes of the matrix phase leading to loss of strength. Therefore, optimal addition of alloying elements is crucial in designing the material for improved hardenability and for stabilizing the de-

\footnotetext{
${ }^{\dagger}$ Corresponding author: decooman@postech.ac.kr
}

sired microstructure. However, at the same time, the alloy system must have a lean chemical composition so as not to cause coating defects during the hot-dip coating process and ensure good weldability. The present contribution mainly focuses on (1) the selective oxidation reactions at the surface and in the sub-surface of martensitic steel during austenitic annealing, (2) the effect of the $\mathrm{Zn}$ bath composition on the oxides present on the martensitic steel prior to hot dipping, and (3) the effect of the hot dipping coating process on the mechanical properties of martensitic steel.

The gas atmosphere of the industrial annealing furnace in continuous hot dip Galvanizing/Galvannealing (GI/GA) lines leads to the reduction of the iron oxides formed during cold rolling and the selective oxidation of the key alloying additions of $\mathrm{Mn}, \mathrm{Al}$ and $\mathrm{Si}$. The presence of filmforming surface oxides at the steel surface prior to hot dipping has been reported as having a significant effect on the wettability of the steel by molten $\mathrm{Zn}$ and their presence may prevent the formation of the $\mathrm{Fe}_{2} \mathrm{Al}_{5-\mathrm{x}} \mathrm{Zn}_{\mathrm{x}}$ inhibition layer. ${ }^{1-5)}$ The formation of surface oxides during 
the annealing of Si-bearing steels is very well documented. $^{2), 6)-10)}$ There are very few direct observations of the formation of the oxides during the annealing, the interaction of the oxides with the $\mathrm{Zn}$ bath and the effect of the oxides on the wetting of the steel surface by the liquid Zn. Khondker et al. and Bellhouse et al. have reported that oxides formed on the surface of TRIP and DP steel can be reduced by the $\mathrm{Al}$ during the dipping process. ${ }^{11), 12}$ ) Meguerian et al. reported the reactive wetting kinetics of $\mathrm{MnO}$ on Mn-bearing DP steel surface. ${ }^{13)}$ The direct observation of the interaction between actual surface oxides present on Advanced High Strength Steel (AHSS), i.e. $a-\mathrm{SiO}_{2}, a-\mathrm{xMnO} . \mathrm{SiO}_{2}, c-\mathrm{MnO} . \mathrm{SiO}_{2}$ and $c-2 \mathrm{MnO} \cdot \mathrm{SiO}_{2}$, and the $\mathrm{Al}$ in the $\mathrm{Zn}$ bath has not yet been reported.

In the present study, the morphology, size, distribution and composition of the oxides formed on low-Si martensitic steel prior to galvanizing were directly observed by High-Resolution Transmission Electron Microscopy (HRTEM) of Focused Ion Beam (FIB) cross-sectional samples, and the interactions between the oxides and the $\mathrm{Zn}$ bath were investigated.

\section{Experimental}

The martensitic steel used in the present work was a full-hard cold-rolled steel with a thickness of $1 \mathrm{~mm}$ containing 0.15 mass $\%$ C, 2.0 mass $\%$ Mn and 0.33 mass $\%$ $\mathrm{Si}$. The sample surface was degreased in a $2 \% \mathrm{NaOH}$ solution and ultrasonically cleaned in iso-propanol prior to the annealing simulation. The hot dip galvanizing (HDG) process simulation was carried out in a HDG simulator. The $10 \% \mathrm{H}_{2}+\mathrm{N}_{2}$ gas atmosphere had a dew point of -35 ${ }^{\circ} \mathrm{C}$. The $\mathrm{Zn}$ bath compositions were $0.13 \% \mathrm{Al}$ and $0.20 \%$ $\mathrm{Al}$ for the simulation of the interactions between steel and the liquid $\mathrm{Zn}$ in conditions comparable to galvannealing and galvanizing, respectively.

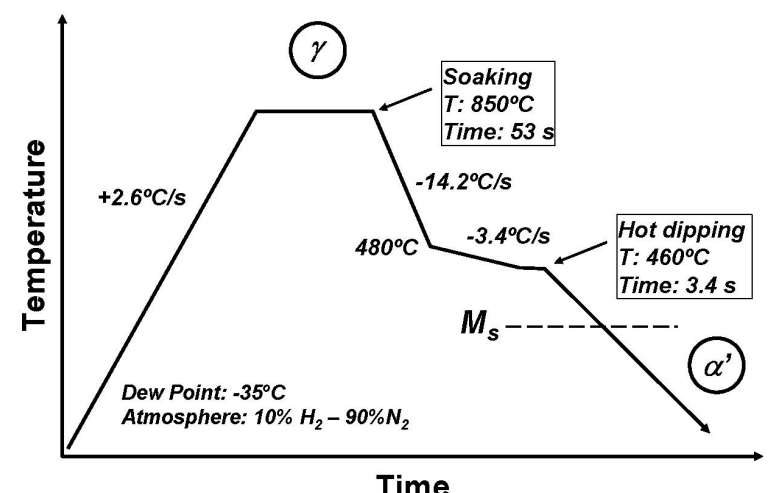

Fig. 1. Schematic of the thermal cycle used for the GI/GA experiments. The $10 \% \mathrm{H}_{2}+90 \% \mathrm{~N}_{2}$ gas atmosphere had a dew point of $-35{ }^{\circ} \mathrm{C}$.
The thermal cycle is shown in Fig. 1. The annealing temperature $\left(850^{\circ} \mathrm{C}\right)$ was in the fully austenitic phase stability range. The soaking time was 53 seconds. The temperature of the $\mathrm{Zn}$ bath was $460{ }^{\circ} \mathrm{C}$ and the dip time was 3.4 seconds. Coated and uncoated samples were analyzed in a $200 \mathrm{keV}$ JEOL JEM-2100F using FIB cross-sectional samples. Tensile specimens were machined from the coated steel panels and tensile tests were performed at room temperature on a Zwick/Roell universal testing machine using a strain rate of $10^{-3} / \mathrm{s}$.

\section{Results and discussion}

A typical cross-sectional view of the surface of the martensitic steel after annealing at $850{ }^{\circ} \mathrm{C}$ is shown in Fig. 2. The surface was partly covered with large oxide particles. In other areas the oxide was present as a thin film (Fig. 2.a). The thick layer with a dark contrast is a protective $\mathrm{Au}$ coating layer used during the FIB sample preparation. Fig. 2.b. shows the microstructure of the larger surface oxide particles in zone A in Fig. 2.a. These lens-shape oxides particles on the surface had a thickness in the range of $35-130 \mathrm{~nm}$. They were covered by the shell with a different composition. Fig. 2.c. is the lattice image of the interface between the lens-shaped particles and the thin surface film (zone $a_{1}$ in Fig. 2.b). The larger particles had an amorphous core and a crystalline shell, which were identified as $a$ - $\mathrm{SiO}_{2}$ and $c$-xMnO. $\mathrm{SiO}_{2}(1 \leq \mathrm{x}<2)$, respectively. The black dotted line in Fig. 2.c indicates the position of the interface between the crystalline $c$-xMnO. $\mathrm{SiO}_{2}$ $(1 \leq \mathrm{x}<2)$ shell and the amorphous $a-\mathrm{SiO}_{2}$ core. The white dotted line indicates the position of the interface between the shell and the steel matrix. Fig. 2.d is a lattice image taken in zone $a_{2}$ of Fig. 2.b.

There is a clear transition layer with a gray contrast in the TEM micrograph visible between the amorphous $a$ - $\mathrm{SiO}_{2}$ core and the crystalline $c$-xMnO. $\mathrm{SiO}_{2}(1 \leq \mathrm{x}<2)$ shell, in which the ratio $\mathrm{x}$ of $\mathrm{Mn}$ to $\mathrm{Si}$ increased, corresponding to the transition from amorphous $a-\mathrm{SiO}_{2}$ to crystalline $c$-xMnO. $\mathrm{SiO}_{2}(1 \leq \mathrm{x}<2)$. Fig. 2.e is a detail of the surface smaller particles and the thin oxide film with a thickness of $\sim 15 \mathrm{~nm}$. The lattice image of the smaller oxides in zone $a_{3}$ of Fig. 2.e is shown in Fig. 2.f. It is amorphous $a$-xMnO.SiO2 with a ratio of $\mathrm{Mn}$ to $\mathrm{Si}$ less than 0.9 . The dotted white line indicates the position of the interface between the amorphous $a$-xMnO. $\mathrm{SiO}_{2}(\mathrm{x}<0.9)$ oxide and the steel matrix. The lattice image of the thin oxide film (Fig. 2.g) in zone $a_{4}$ of Fig. 2.e was identified as crystalline $c$-xMnO. $\mathrm{SiO}_{2}$, with a $\mathrm{Mn} / \mathrm{Si}$ ratio larger than 1. The position of the interface between the oxide film and the matrix is indicated by the white dotted line. The 


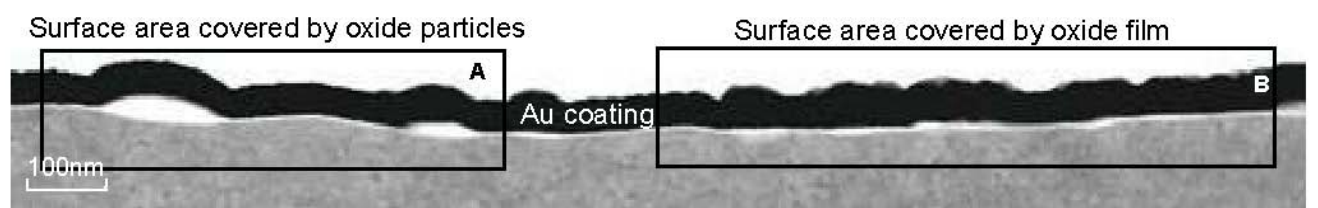

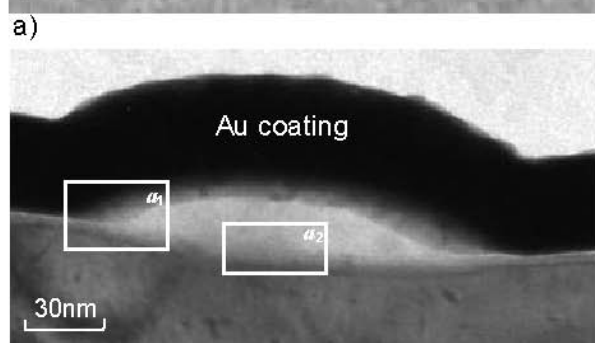

b)

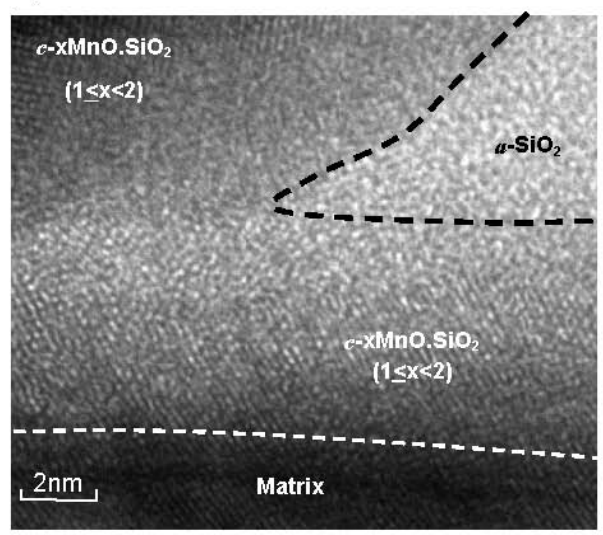

c)

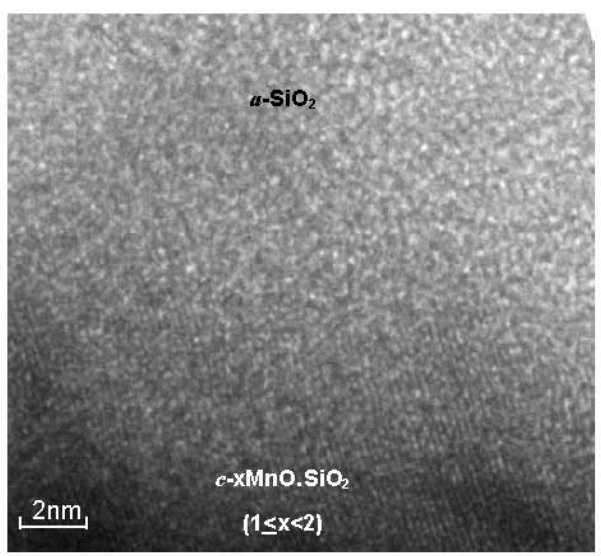

d)

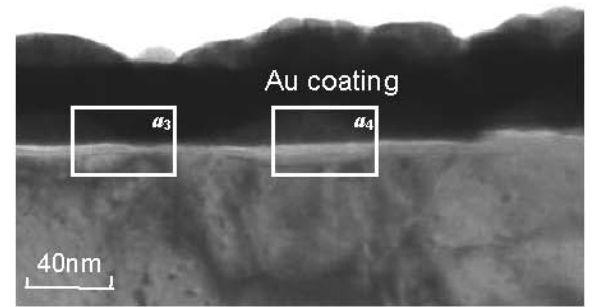

e)

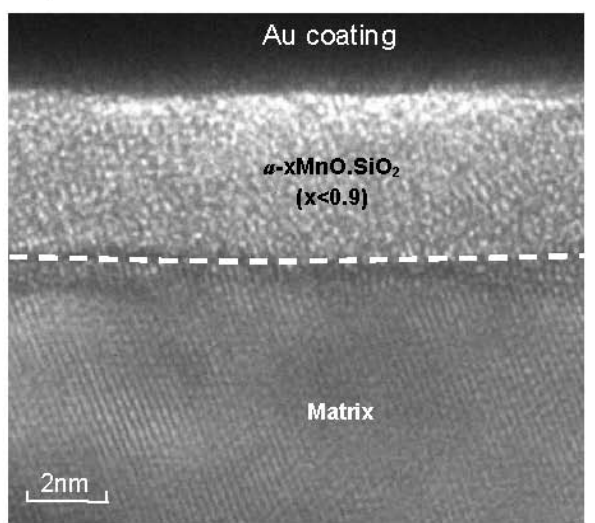

f)

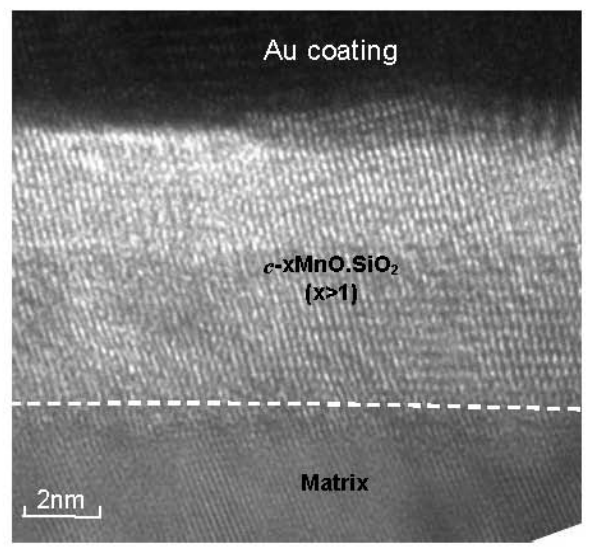

g)

Fig. 2. Cross-sectional TEM micrographs for martensitic steel after annealing prior to hot dipping. (a) Overview of the surface after annealing at $850{ }^{\circ} \mathrm{C}$, a temperature in the full austenite phase temperature range. At the surface, large oxide particles (zone A) and a thin oxide film (zone B) are clearly visible. (b) Micrograph of the larger oxide particle in zone A. (c) Lattice image of the interface between oxide particles, oxide film and matrix in zone $a_{1}$ of (b). The dotted black line indicates the position of the interface between the core of an amorphous $a-\mathrm{SiO}_{2}$ oxide and its crystalline $c$ - $\mathrm{xMnO} . \mathrm{SiO}_{2}(1 \leq \mathrm{x}<2)$ shell. The dotted white line indicates the position of the steel $/ c$-xMnO. $\mathrm{SiO}_{2}(1 \leq \mathrm{x}<2)$ interface. (d) The transition from the amorphous $a-\mathrm{SiO}_{2}$ oxides core to the crystalline $c$-xMnO. $\mathrm{SiO}_{2}(1 \leq \mathrm{x}<2)$ shell in zone $a_{2}$ in (b). (e) Detailed micrograph of the thin oxide film in zone $\mathrm{B}$ of (a). (f) Lattice image of the thin amorphous $a$-xMnO. $\mathrm{SiO}_{2}(\mathrm{x}<0.9)$ oxide in zone $a_{3}$ of (c). The dotted white line indicates the position of the steel $/ a$-xMnO. $\mathrm{SiO}_{2}(\mathrm{x}<0.9)$ interface. $(\mathrm{g})$ Lattice image of the thin oxide film in zone $a_{4}$ in (c). The dotted white line indicates the position of the steel $/ c-x M n O \cdot \mathrm{SiO}_{2}(\mathrm{x}>1)$ oxide film. 


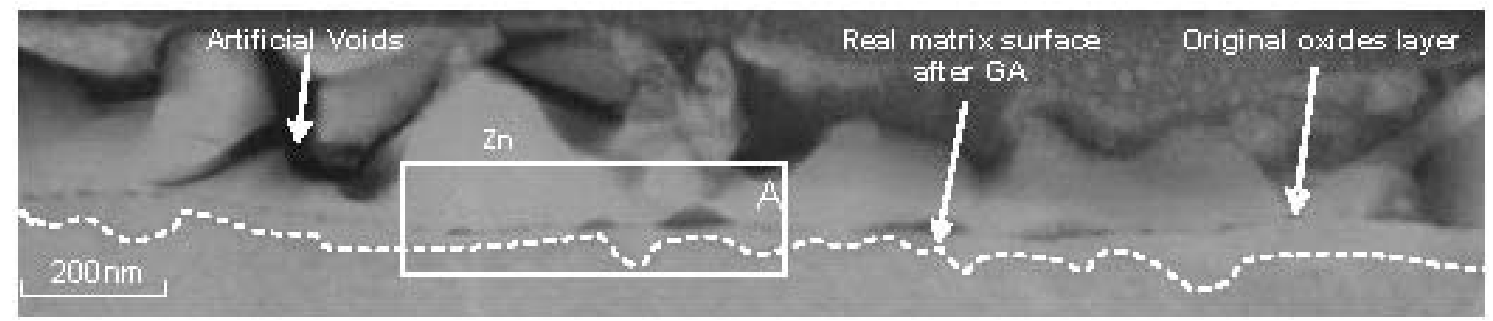

Fig. 3. Cross-sectional TEM micrograph of the steel/coating interface after hot dipping in $\mathrm{Zn}-0.13 \mathrm{Al} \%$. The dotted white line indicates the position of the steel/Zn interface. The string of isolated lens-shaped particles clearly indicates the initial position of the steel surface prior to dipping. The initial crystalline oxide film was clearly removed by a reactive interaction between these surface oxides and the liquid $\mathrm{Zn}$. $\mathrm{Zn}$ can therefore penetrate the oxide film and directly react with the steel matrix. Note that the "artificial" voids in the micrographs are solely due to specimen preparation, as most of the $\mathrm{Zn}$ layer must be removed prior to FIB sample preparation.

present observations confirm similar observations reported previously by Mahieu et al. . $^{2}$ and Ramadeva et al. ${ }^{9}$

Fig. 3 shows the $\mathrm{Zn} / \mathrm{steel}$ interface after hot dipping in $\mathrm{Zn}-0.13 \% \mathrm{Al}$ at $460{ }^{\circ} \mathrm{C}$. The continuous crystalline oxide films observed after the annealing were almost fully removed after GA. However, the larger amorphous $a-\mathrm{SiO}_{2}$ oxides particles and smaller amorphous particles were still present embedded in the $\mathrm{Zn}$ coating. A dotted white line indicates the original position of the steel surface after GA. It is clear that the liquid $\mathrm{Zn}$ penetrated through the oxide film and surrounded the amorphous particles. The depth of the former surface "etched" away by the liquid $\mathrm{Zn}$ during the dipping process was approximately $60 \mathrm{~nm}$.

A detailed microstructure of zone A in Fig. 3 is shown in the micrographs shown in Fig. 4. Fig. 4.a. gives an overview of the oxides layers on the steel surface. Fig. 4.b is a lattice image of the original crystalline film (zone $a_{1}$ of Fig. 4.a) after hot dipping. Most of this layer was dissolved due to reduction by the $\mathrm{Al}$ in the $\mathrm{Zn}-0.13 \% \mathrm{Al}$ bath. The particle with the light contrast was $\mathrm{xMnO} \cdot \mathrm{Al}_{2} \mathrm{O}_{3}$ $(\mathrm{x}=0.8)$. It is the product resulting from the reduction of the crystalline $c$-xMnO.SiO $2(x>1)$ by $\mathrm{Al}$. The dotted white line in Fig. 4.c indicates the position of the interface between the matrix and $\mathrm{Zn}$ layer, in the area corresponding to zone $a_{2}$ in Fig. 4.a. After the crystalline oxides were reduced by $\mathrm{Al}$, they very likely dissolved in the liquid $\mathrm{Zn}$ as they were not detected after hot dipping. The $\mathrm{Zn}$ penetrated through the oxide film and, as the Fe dissolved in the liquid $\mathrm{Zn}$, the $\mathrm{Zn}$ could flow around the larger amorphous oxide particles.

A lattice image of an amorphous $a$-xMnO. $\mathrm{SiO}_{2}(\mathrm{x}<0.9)$ particle, corresponding to the zone $a_{3}$ of Fig. 4.a, is shown in Fig. 4.d. Amorphous particles with a light contrast are believed to be partially reduced amorphous $a-\mathrm{xMnO} . \mathrm{SiO}_{2}$

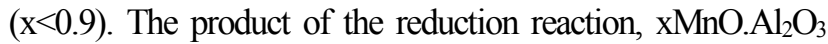
$(\mathrm{x}=0.6)$, was found close to these amorphous $a-\mathrm{xMnO} \cdot \mathrm{SiO}_{2}$ $(\mathrm{x}=0.3)$ oxides. Fig. 4.e shows a detailed microstructure of what was originally an amorphous $a-\mathrm{SiO}_{2}$ particle with a crystalline $c$-xMnO. $\mathrm{SiO}_{2}(1 \leq \mathrm{x}<2)$ shell, corresponding zone $a_{4}$ of Fig. 4.a. The light contrast phase forming around the amorphous $a-\mathrm{SiO}_{2}$ particle is $\mathrm{xMnO} \cdot \mathrm{Al}_{2} \mathrm{O}_{3}$ $(0.2<\mathrm{x}<1.25)$ after the hot dipping, as the original crystalline $c$-xMnO. $\mathrm{SiO}_{2}(1 \leq \mathrm{x}<2)$ shell was reduced by $\mathrm{Al}$. The amorphous $a-\mathrm{SiO}_{2}$, corresponding to zone $a_{5}$ of Fig. 4.a, is shown in Fig. 4.f. The lattice image of amorphous $a-\mathrm{SiO}_{2}$ clearly shows that this particular oxide was not reduced by $\mathrm{Al}$ during dipping.

The microstructure of the coating/steel interface after hot dipping in $\mathrm{Zn}-0.20 \% \mathrm{Al}$ at $460{ }^{\circ} \mathrm{C}$ is shown in Fig. 5. The thick layer with a darker gray contrast in Fig. 4.a is the inhibition layer. Its thickness was irregular. The original steel surface was "etched" by the liquid $\mathrm{Zn}$, and the residual oxides were found to be entirely embedded in the inhibition layer (Fig. 5.a). Fig. 5.b shows a lattice image of the inhibition layer, corresponding to zone $\mathrm{A}$ in Fig. 5.a. The composition of the inhibition layer was $\mathrm{Fe}_{2} \mathrm{Al}_{5-\mathrm{x}} \mathrm{Zn}_{\mathrm{x}}(0.12<\mathrm{x}<0.6)$. The dotted white line in Fig. 5.c indicates the position of the interface between the inhibition layer and the matrix. The detailed microstructure of zone B in Fig. 5.a is shown in Fig. 6. The particles with the white contrast in Fig. 6.a are the initial oxides that can still be observed after hot dipping in $\mathrm{Zn}-0.20 \% \mathrm{Al}$. The dotted lines indicate the steel/coating interface position after hot dipping. Fig. 6.b shows the microstructure for amorphous $a-\mathrm{SiO}_{2}$ particles, which had a $c$-xMnO. $\mathrm{SiO}_{2}$ $(1 \leq \mathrm{x}<2)$ oxide shell prior to hot dipping (e.g. in zone $a_{1}$ of Fig. 1.a). The amorphous $a-\mathrm{SiO}_{2}$ particles were still present after dipping, but the $c$-xMnO. $\mathrm{SiO}_{2}(1 \leq \mathrm{x}<2)$ oxide

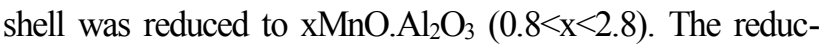
tion is very likely by the $\mathrm{Al}$ present in the $\mathrm{Zn}-0.20 \mathrm{Al} \%$ bath. Fig. 6.c shows some residue of the initial oxides film (zone $a_{2}$ in Fig. 6.a). The dotted white lines indicate 

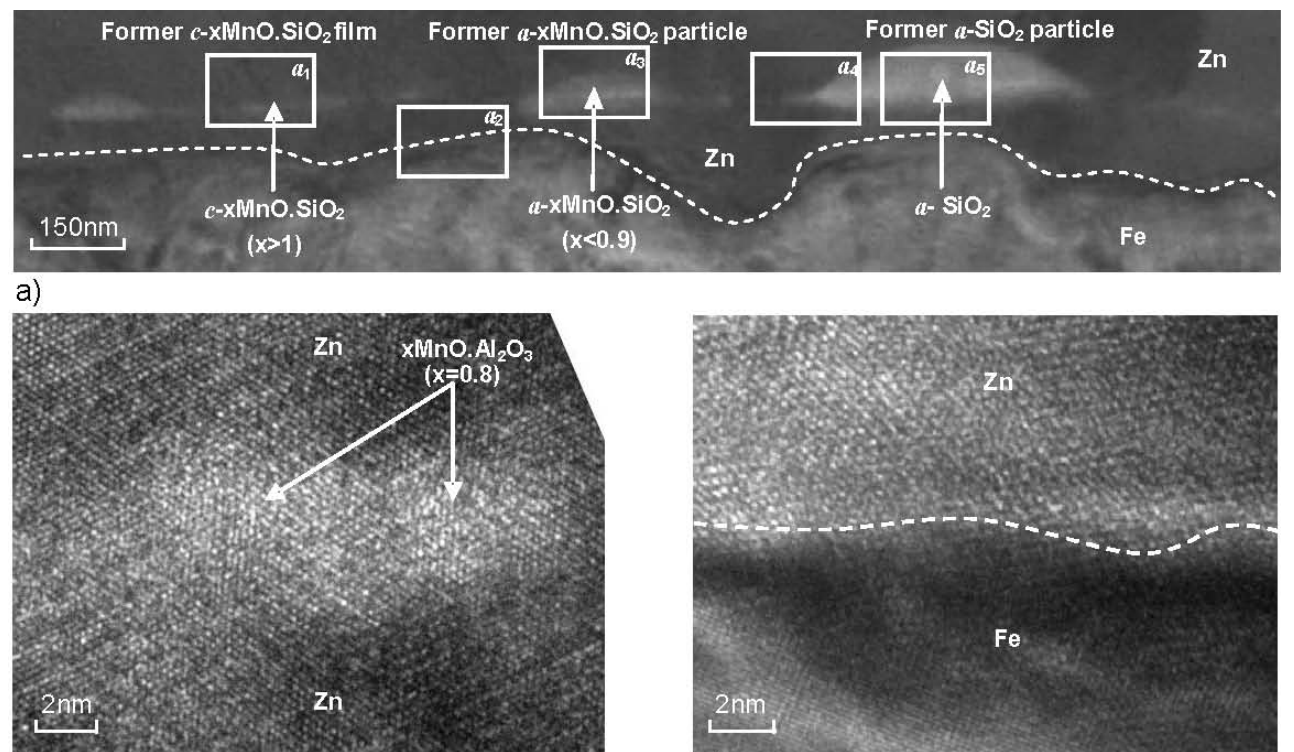

b)
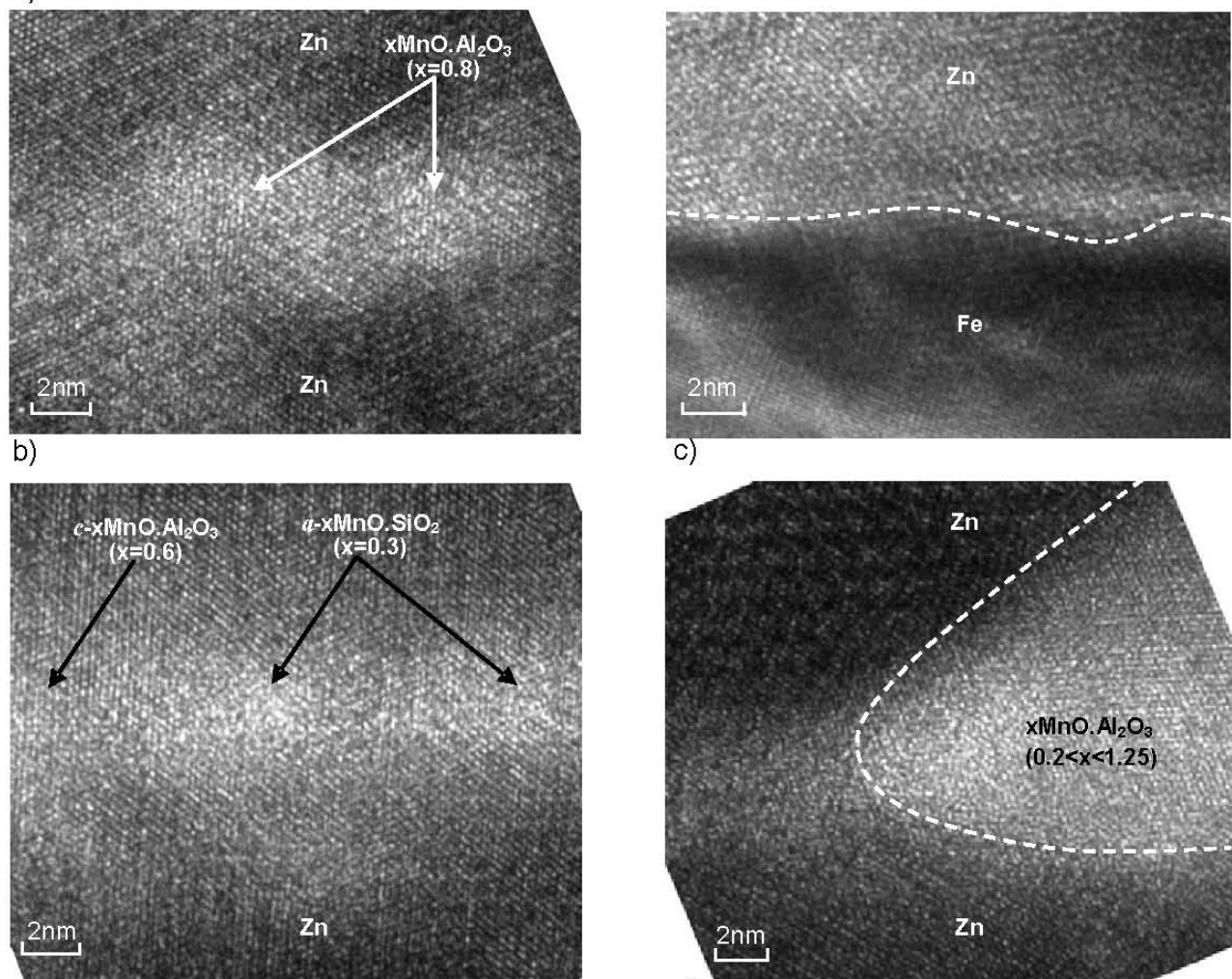

d)

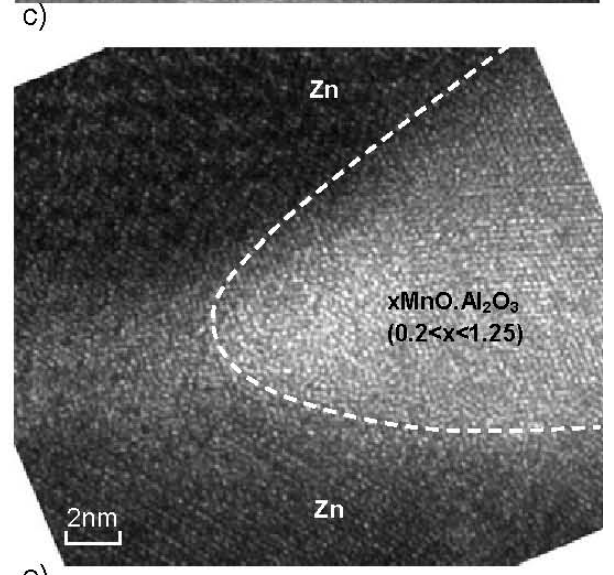

e)

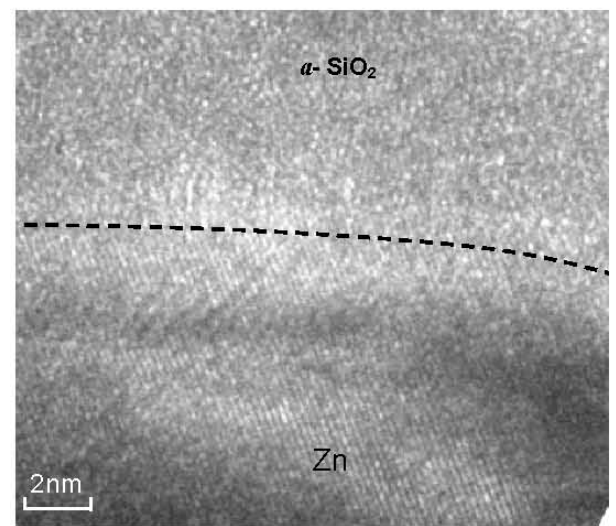

f)

Fig. 4. (a) Cross-sectional TEM micrograph of the martensitic steel/coating interface after hot dipping in $\mathrm{Zn}-0.13 \% \mathrm{Al}$. The white dotted line indicates the steel/coating interface. Note the absence of the $\mathrm{Fe}_{2} \mathrm{Al}_{5-\mathrm{x}} \mathrm{Zn}_{\mathrm{x}}$ inhibition layer. (b) Lattice image for $c$-xMnO. $\mathrm{Al}_{2} \mathrm{O}_{3}(\mathrm{x}=0.8)$ formed by reduction of the $c$-xMnO. $\mathrm{SiO}_{2}(\mathrm{x}>1)$ oxide by $\mathrm{Al}$. (c) Lattice image of the steel/Zn interface. The $\mathrm{Zn}$ has penetrated through the crystalline oxides after their reduction by Al. (d) Lattice image of small residual $a$-xMnO.SiO $\mathrm{x}_{2}$ $(\mathrm{x}<0.9)$ oxide particles of the zone $a_{3}$ in (a). The $a$-xMnO. $\mathrm{SiO}_{2}(\mathrm{x}<0.9)$ oxides cannot be completely reduced by Al. (e) Lattice image of the $c$-xMnO. $\mathrm{Al}_{2} \mathrm{O}_{3}$ oxide shell around an amorphous $a-\mathrm{SiO}_{2}$ particles. (f) Lattice image of an $a$ - $\mathrm{SiO}_{2}$ oxide particle embedded in the $\mathrm{Zn}$. 


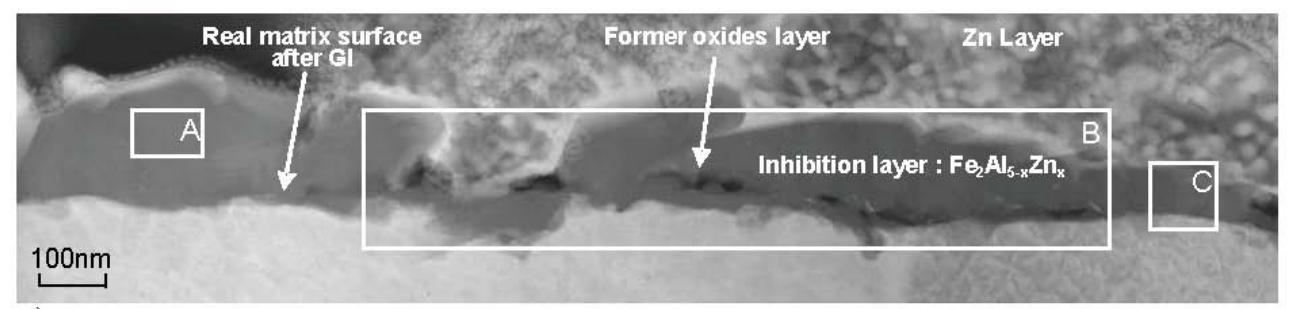

a)

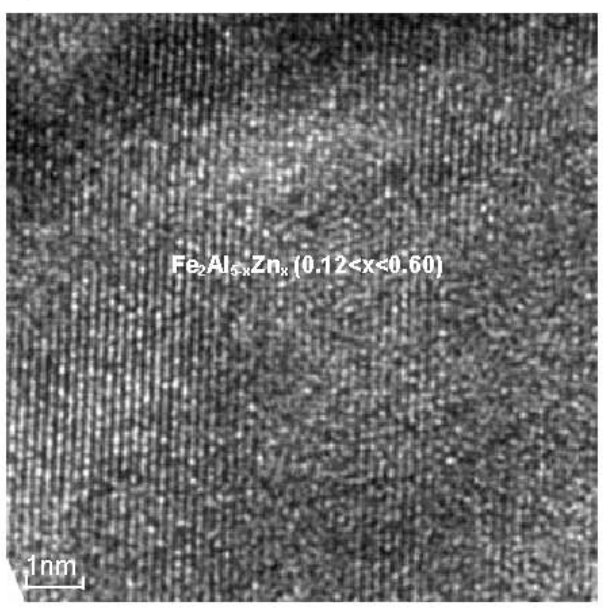

b)

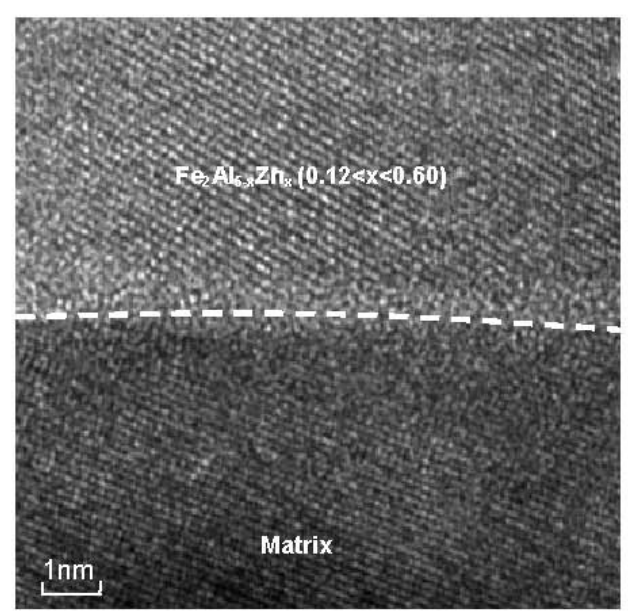

c)

Fig. 5. Cross-sectional TEM micrographs of the steel/inhibition layer interface after hot dipping of the martensitic steel in $\mathrm{Zn}-0.2 \% \mathrm{Al}$. (a) Overview of the inhibition layer with embedded residual oxides. (b) Lattice image of the $\mathrm{Fe}_{2} \mathrm{Al}_{5-\mathrm{x}} \mathrm{Zn}_{\mathrm{x}}$ inhibition layer in zone $\mathrm{A}$ in (a). (c) $\mathrm{Steel} / \mathrm{Fe}_{2} \mathrm{Al}_{5-\mathrm{x}} \mathrm{Zn}_{\mathrm{x}}$ interface in zone $\mathrm{C}$ of (a).

the position of the initial crystalline oxide film, which was almost completely removed during the hot dipping. The $\mathrm{Zn}$ coating side of the $\mathrm{Fe}_{2} \mathrm{Al}_{5-\mathrm{x}} \mathrm{Zn}_{\mathrm{x}}$ inhibition layer had a value for $\mathrm{x}$ in the range of $0.44-0.60$. The matrix-side of the inhibition layer was less enriched in $\mathrm{Zn}$ rich. Its $\mathrm{x}$ value was in the range of $0.14-0.32$. Fig. $6 . \mathrm{d}$ shows a detailed microstructure of an initially thicker crystalline oxide layer (zone $a_{3}$ in Fig. 6.a). These thicker crystalline $c$-xMnO. $\mathrm{SiO}_{2}(\mathrm{x}=1.41)$ oxides initially present on the surface prior to the hot dipping were not completely reduced due to their thickness and they could therefore still be observed embedded in the inhibition layer after hot dipping.

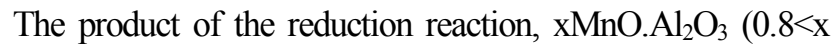
$<2.8$ ), is also shown in Fig. 6.d.

Van De Putte et al. recently used sessile drop angle measurements to analyze the effects of Si-Mn oxides on the wettability of the Si-bearing steel sheets by analysis of the wetting angel. ${ }^{14)}$ Khondker et al. and Bellouse et al. have suggested that $\mathrm{MnO}$ oxides can be reduced by Al during hot dipping, ${ }^{11), 12}$ according to the following reaction:

$$
3 \mathrm{MnO}+2 \mathrm{Al}_{\text {sol }} \Rightarrow \mathrm{Al}_{2} \mathrm{O}_{3}+3 \mathrm{Mn}_{\text {sol }}
$$

However, the reactive interaction between $\mathrm{Al}$ in the liquid $\mathrm{Zn}$ and the $\mathrm{xMnO} . \mathrm{SiO}_{2}$ compound oxides was not considered. An alternative two-step reduction process occurring during hot dipping could be as follows:

$$
\begin{aligned}
& \mathrm{Mn}_{2} \mathrm{SiO}_{4}+2 \mathrm{Al}_{\text {sol }} \Rightarrow[\mathrm{MnO}] \mathrm{MnSiO}_{3}+2 \mathrm{Al}_{\text {sol }} \\
& \mathrm{Mn}_{2} \mathrm{SiO}_{4}+2 \mathrm{Al}_{\text {sol }} \Rightarrow\left[\mathrm{Al}_{2} \mathrm{O}_{3}\right]+\mathrm{Mn}_{\text {sol }}+\mathrm{Si}_{\text {sol }} \\
& \mathrm{Mn}_{2} \mathrm{SiO}_{4}+2 \mathrm{Al}_{\text {sol }} \Rightarrow\left[\mathrm{MnAl}_{2} \mathrm{O}_{3}\right]+\mathrm{Mn}_{\text {sol }}+\mathrm{Si}_{\text {sol }}
\end{aligned}
$$

Note that this formal reaction mechanism takes into account two compound oxides $\mathrm{MnO}^{-\mathrm{SiO}_{2}}$ and $2 \mathrm{MnO} \cdot \mathrm{SiO}_{2}$. The first reaction is strictly speaking not a reduction reaction, but it emphasizes the fact that the reduction of $2 \mathrm{MnO} \mathrm{SiO}_{2}$ goes via the intermediate formation of $\mathrm{MnSiO}_{3}$. In addition, the proposed reactions underline the importance of the very high thermodynamic stability of the $\mathrm{MnAl}_{2} \mathrm{O}_{4}$ spinel in driving the reduction reactions. It also suggests how the oxides can appear to dissolve into the liquid $\mathrm{Zn}$, leaving $\mathrm{MnAl}_{2} \mathrm{O}_{4}$ as a reaction product.

The mechanical properties of hot dipped martensitic steels were evaluated by means of uni-axial tensile tests. Engineering stress-strain curves for the as-quenched and galvanized specimens are shown in Fig. 7. The stress- 


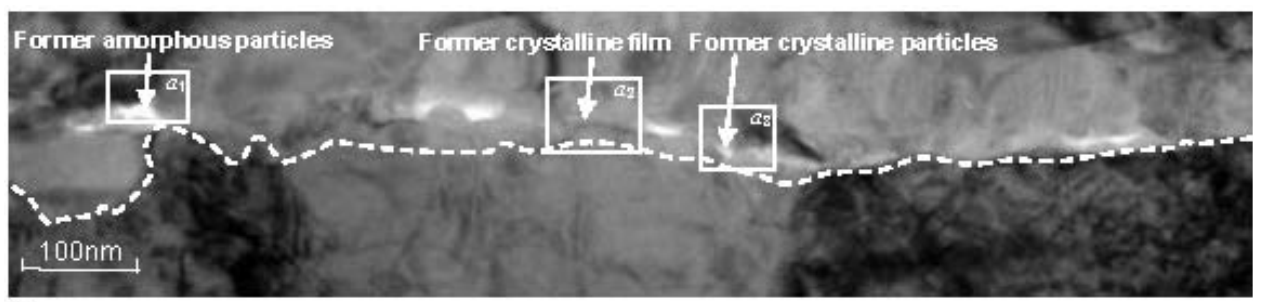

a)

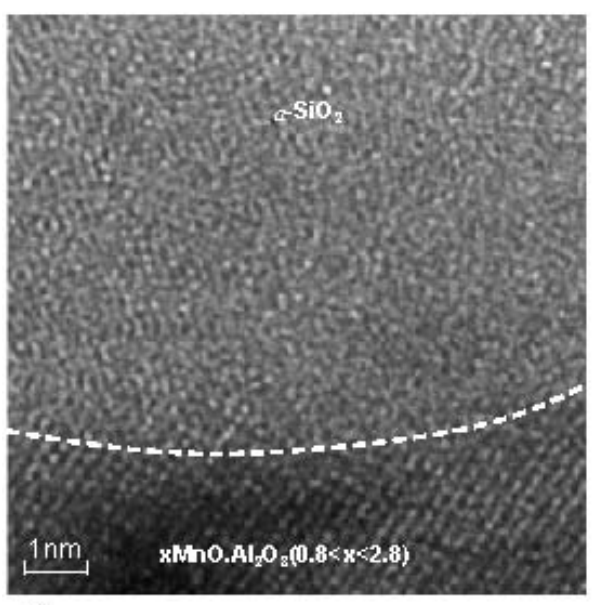

b)

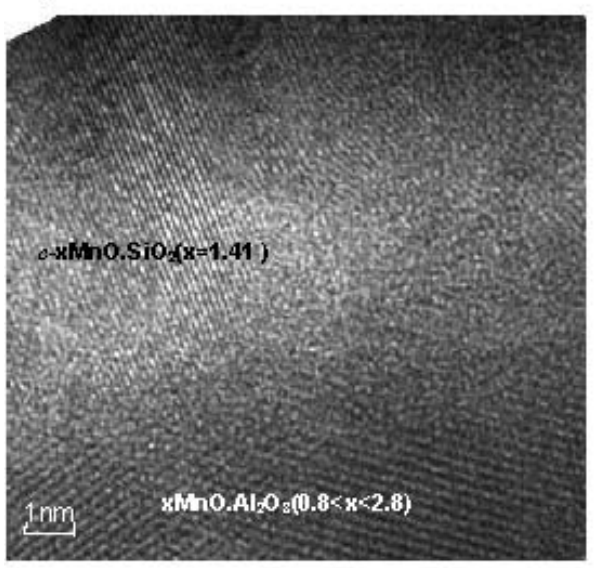

d)

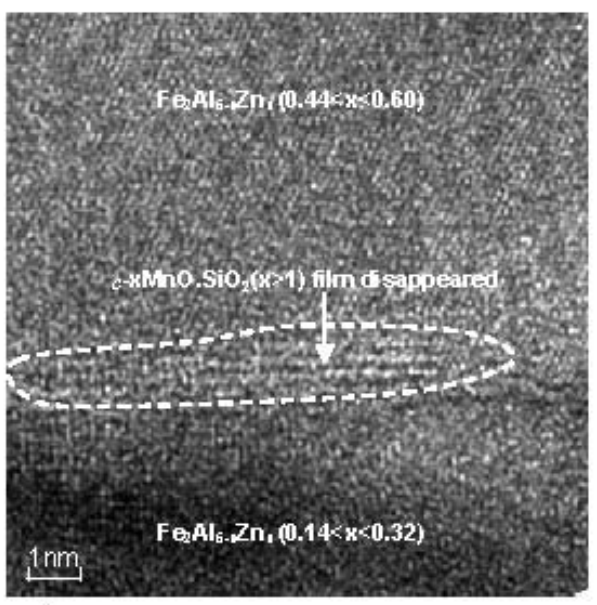

c)

Fig. 6. (a) Cross-sectional TEM image of zone B in Fig. 5.a, showing oxides particles embedded in the inhibition layer. The dotted white line indicates the position of the steel/inhibition layer after dipping. Particles with a light contrast are the initial oxides particles. (b) Lattice image of the amorphous oxide particles of zone $a_{1}$ in a. The amorphous $a$ - $\mathrm{xMnO} \mathrm{SiO} \mathrm{S}_{2}(\mathrm{x}<0.9)$ and $a-\mathrm{SiO}_{2}$ particles were not reduced by Al. (c) Lattice image of a residue of the crystalline $c$ - $\mathrm{xMnO} \mathrm{SiO} \mathrm{S}_{2}(\mathrm{x}>1)$ oxide film in zone $a_{2}$ of (a). (d) Lattice image of a small crystalline $\mathrm{xMnO} . \mathrm{SiO}_{2}(\mathrm{x}>1)$ particle partially reduced by $\mathrm{Al}$. The particle

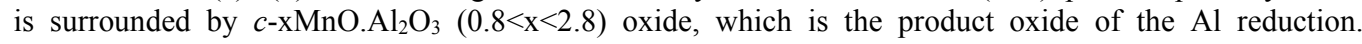

strain curve of the as-quenched martensite shows the characteristic continuous stress-strain curve for low-carbon lath martensite. Its ultimate tensile strength (UTS) and total elongation were $1460 \mathrm{MPa}$ and $5.8 \%$, respectively. The hot dip process resulted in a significant decrease of the UTS by about $300 \mathrm{MPa}$. The total elongation increased to $12 \%$. The difference in mechanical properties between as-quenched and galvanized specimen was due to the presence bainite. During the slow cooling from $480{ }^{\circ} \mathrm{C}$ to the dipping temperature of $460{ }^{\circ} \mathrm{C}$, part of the untransformed austenite inevitably transformed to bainite. The presence of bainite in the martensite matrix reduced the strength of the steel, and improved the ductility. This implies that the strength and elongation of martensitic steel can be con- 


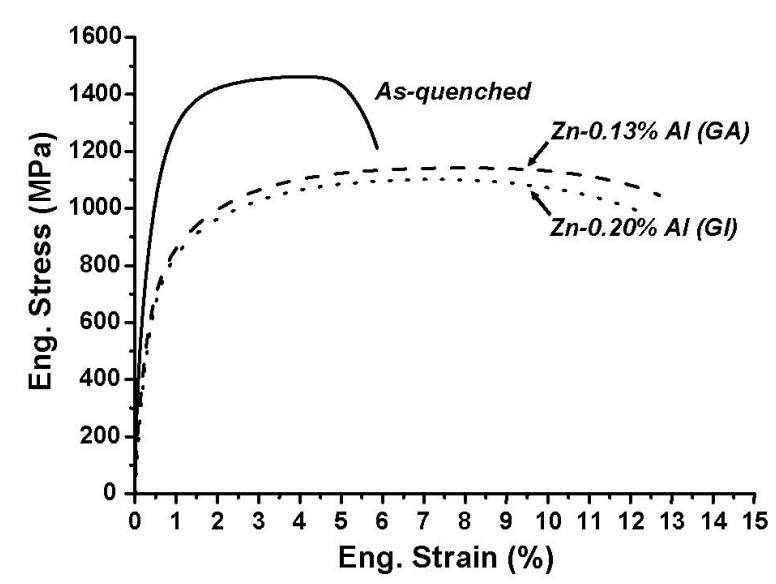

Fig. 7. Engineering stress-strain curves for water quenched martensite and galvanized materials.

trolled by adjusting the process parameters within the process window available in a conventional hot dip galvanizing processing line.

\section{Conclusions}

The selective oxidation of $\mathrm{Si}$ and $\mathrm{Mn}$ on the surface of a martensitic steel annealed in a $10 \% \mathrm{H}_{2}+\mathrm{N}_{2}$ gas atmosphere in conditions of external oxidation, i.e. with a dew point of $-35{ }^{\circ} \mathrm{C}$, resulted in the formation of amorphous $a-\mathrm{SiO}_{2}$ particles with a crystalline $\mathrm{xMnO}^{-\mathrm{SiO}_{2}}(1 \mathrm{x}<2)$ oxide shell, small amorphous a-xMnO. $\mathrm{SiO}_{2}(\mathrm{x}<0.9)$ particles and a very thin crystalline c-xMnO. $\mathrm{SiO}_{2}(\mathrm{x}>1)$ film at the steel surface.

During hot dipping in $\mathrm{Zn}-0.13 \% \mathrm{Al}$, the thin $\mathrm{c}-\mathrm{xMnO} . \mathrm{SiO}_{2}$ $(\mathrm{x}>1)$ crystalline oxide film was reduced by $\mathrm{Al}$ and dissolved in the liquid $\mathrm{Zn}$. The crystalline $\mathrm{xMnO}^{-\mathrm{SiO}_{2}}(1 \mathrm{x}<2)$ oxides shell of amorphous $a-\mathrm{SiO}_{2}$ particles was reduced to $\mathrm{xMnO} . \mathrm{Al}_{2} \mathrm{O}_{3}(0.2<\mathrm{x}<1.25)$. The amorphous $a$-xMnO. $\mathrm{SiO}_{2}$ $(\mathrm{x}<0.9)$ and $a-\mathrm{SiO}_{2}$ particles were not reduced during hot dipping and remained embedded in the $\mathrm{Zn}$ layer. No inhibition layer was formed during dipping in $\mathrm{Zn}-0.13 \% \mathrm{Al}$.

After hot dipping in $\mathrm{Zn}-0.20 \% \mathrm{Al}$, the thin $\mathrm{c}-\mathrm{xMnO} . \mathrm{SiO}_{2}$ $(\mathrm{x}>1)$ crystalline oxide film was reduced by $\mathrm{Al}$ and dissolved in the liquid $\mathrm{Zn}$. The crystalline c-xMnO.SiO $2(1$ $\mathrm{x}<2$ ) oxides shell of amorphous $a-\mathrm{SiO}_{2}$ particles was re-

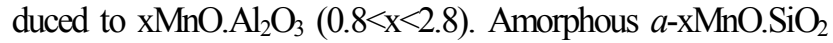
$(\mathrm{x}<0.9)$ and $a-\mathrm{SiO}_{2}$ particles were not reduced and were imbedded in the $\mathrm{Fe}_{2} \mathrm{Al}_{5-\mathrm{x}} \mathrm{Zn}_{\mathrm{x}}$ inhibition layer.

The observed results clearly show that $\mathrm{Al}$ in the $\mathrm{Zn}$ bath plays a critical role in reducing the crystalline $c$ $\mathrm{xMn} . \mathrm{SiO}_{2}(\mathrm{x}>1)$ compound oxides formed at the surface of a martensitic steel during austenitic annealing. The amorphous $a$-xMnO.SiO $2(\mathrm{x}<0.9)$ and $a-\mathrm{SiO}_{2}$ oxides particles were essentially unaffected by the hot dipping.

\section{References}

1. A. R. Marder, Progr. Mater. Sci., 45, 193 (2000).

2. J. Mahieu, S. Claessens, and B. C. De Cooman, Metall. Mater. Trans. A, 32A, 2905 (2001).

3. X. Vanden Eynde, J. P. Servais, and M. Lamberigts, Surf. Interface Anal., 35, 1004 (2003).

4. Y. F. Gong, S. Birosca, Han S. Kim, and B. C. De Cooman, J. Microsc., 230, 424 (2008).

5. J. Mahieu, S. Claessens, B. C. De Cooman, and F. Goodwin, Proceedings of the 6th International Conference on Zinc and Zinc Alloy Coated Steel Sheet (Galvatech), p. 529, M. A. Baker Editor, Association for Iron and Steel Technology, Chicago, Illinois (2004).

6. Y. F. Gong, Han S. Kim, and B. C. De Cooman, ISIJ International, 49, 557 (2009).

7. Y. F. Gong, Han S. Kim, and B. C. De Cooman, ISIJ International, 48, 1745 (2008).

8. Xiang Shu Li, Sung-Il Baek, Chang-Seok Oh, Sung-Joon Kim, and Young-Woon Kim, Scripta Mater., 57, 113 (2007).

9. C. Ramadeva Shastry, John A. Rotole and Thomas W. Kaiser, Proceedings of the 7th International Conference on Zinc and Zinc Alloy Coated Steel Sheet (Galvatech), p. 403, Association for Iron and Steel Technology, Osaka, Japan (2007).

10. D. Huin, P. Flauder, and J. B. Leblond, Oxidation of Metals, 64, 132 (2005).

11. R. Khondker, A.I. Mertens, and J. R. McDermid, Mater. Sci. Eng. A, 463, 157 (2007).

12. E. M. Bellouse, A.I. Mertens, and J.R. McDermid, Mater. Sci. Eng. A, 463, 147 (2007).

13. R. J. Meguerian and J. R. McDermid, Materials Science and Technology 2007 Conference and Exhibition (MS\& T'07), p. 569, the Minerals, Metals \& Materials Society (TMS), Detroit, USA (2007).

14. T. Van De Putte, D. Loison, J. Penning, and S. Claessens, Metall. Mater. Trans. A, 39A, 2875 (2009).

15. J. Mahieu, Doctoral Thesis, p. 79, Ghent University, Ghent, Belgium (2006). 